\title{
PARLAMENTO Y POLÍTICA EN LA SEVILLA DEL SIGLO XIX. MANUEL SÁNCHEZ SILVA FRENTE AL PROTECCIONISMO CATALÁN Y LOS FUEROS VASCOS.
}

\section{PARLIAMENT AND POLITICS IN THE XIX CENTURY SEVILLA}

\author{
Eduardo J. Alonso Olea \\ Universidad del País Vasco/Euskal Herriko Unibertsitatea
}

\begin{abstract}
Recensión de: CARO CANCELA, Diego. Parlamento y politica en la Sevilla del siglo XIX. Manuel Sánchez Silva frente al proteccionismo catalán y los fueros vascos. Sevilla: Diputación de Sevilla, 2016, 311 pp.
\end{abstract}

Es un lugar común en la historiografia sobre los fueros aludir a los debates mantenidos alrededor de ellos en diversos foros. Uno de los más destacados tradicionalmente fue sin duda el sostenido en 1864, en el Senado, entre Pedro de Egaña y Joaquín Barroeta Aldamar, por un lado, y por otro un senador andaluz, Manuel Sánchez Silva. Ya menos conocido, aunque los expertos en el tema no lo suelan olvidar, es el mantenido años atrás, en 1849, en el Congreso en el que tuvo como contendientes dialécticos, sobre el mismo asunto de los Fueros, a Ascensio Ignacio de Altuna, Francisco José de las Rivas y Toribio de Areitio, diputados, por cierto, de escasa participación en el Hemiciclo, en defensa de los Fueros frente a Manuel Sánchez Silva.

Desde la historiografia vasca, por lo tanto, se ha centrado especial atención al discurso fuerista y ha ejemplificado el de Sánchez Silva como ejemplo de discurso antifuerista, centralista, con larga tradición en las Cortes, como otros debates mucho más recientes han puesto de manifiesto. En todo caso, como indicamos, se ha abordado el papel de Barroeta Aldamar o de Egaña; pero una sombra en estos estudios era ver de cerca al "otro", es decir, al insistente diputado y luego senador andaluz, verdadero "martillo" de los Fueros.

Y la cuestión, esa sí que olvidada hasta ahora, es, desde nuestra perspectiva, ¿qué interés tenía Sánchez Silva en el asunto foral?, ¿por qué estuvo durante décadas manteniendo una postura tan contraria a los Fueros? En definitiva, ¿quién fue Manuel Sánchez Silva?

Pues a contestar esa pregunta se dirige el libro de Diego Caro Cancela. En efecto, desde la historiografia vasca se ha ignorado la propia figura de Sánchez Silva, dejándolo en un mero papel de crítico acérrimo de los Fueros, pero su vida y su actividad parlamentaria, como destaca Diego Caro, da para muchísimo más. De hecho, si nos fijamos en el título, el autor aborda varios aspectos de la vida de la persona y del personaje. Por una parte, su vida politica y parlamentaria, él mismo reconoce que es una biografia parlamentaria, en el contexto de la provincia de Sevilla del siglo XIX, y dentro de su labor parlamentaria destacan, sobre todo, los debates tenidos no sólo al respecto de los Fueros vascos, aspecto muy conocido por la historiografia vasca y por lo tanto en nuestro entorno menos 
original, y otro -basado en una crítica semejante- al respecto del proteccionismo catalán, muy criticado por Sánchez Silva en la medida en que esa política proteccionista respecto a los productos textiles producia el enriquecimiento catalán en perjuicio del resto de los españoles que debían de pagar un gran sobre precio para proteger una industria muy localizada. Sin ser extraordinariamente originales los planteamientos del diputado sevillano no deja de ser desde luego interesante el punto de conexión entre ambos aspectos a la hora de defender la igualdad de todos los españoles.

Pero el autor no sólo profundiza en estos debates parlamentarios más o menos conocidos, sino que aborda la figura de Sánchez Silva de manera más global, puesto que analiza, dentro de su dilatada vida parlamentaria, los procesos electorales que le permitieron ser diputado y senador desde 1841, con referencias a su paso como concejal y luego alcalde de Jerez antes de ser diputado. Este aspecto es especialmente interesante por cuanto el autor muestra y analiza, entre 1841 y 1881 en que fallece, los mecanismos que le permitieron ganar, y a veces perder, elecciones, por lo que nos ilustra muy bien los mecanismos de promoción politica y, teniendo en cuenta que Sánchez Silva primero se presentó por Cádiz y luego "saltó" a su natal Sevilla, los diversos mecanismos de organización de las elecciones en distintos momentos, momentos desde luego convulsos. Es de especial interés las fuentes utilizadas en este aspecto, a veces muy difícil de analizar y más todavía en un periodo tan largo y con diversas coyunturas politicas, desde los principios de la monarquía liberal hasta el comienzo de la Restauración.

Se echa de menos que el autor haya incidido más en el aspecto personal, aunque lógicamente nos hace un perfil biográfico (nacimientos, matrimonios, rentas,...), pero en este campo sin duda la principal dificultad ha sido la falta de fuentes a su alcance. Todos los que hemos realizado biografias sabemos que a veces, por mucho que nos esforcemos, la falta de un archivo personal, de fuentes biográficas directas, en definitiva, nos oculta a la persona, aunque tengamos todos los datos del "personaje". En la medida en que el biografiado no dejó rastros de algunos aspectos de su vida se nos presenta una especie de muro sobre el que no podemos pasar sin entrar en el campo de lo fantasioso. De hecho, el mismo autor reconoce la falta de explicación o de causa aparente de que Sánchez Silva fuera tan recurrente en la crítica a los Fueros vascos, crítica que fue cuajando por otra parte en la opinión pública española -y que sigue haciéndolo- puesto que sólo tiene su propio testimonio en el debate sostenido en 1864, pero, como decimos, la falta de fuentes personales sin duda nos impide llegar más allá del dicho en el hemiciclo por el propio senador. Es cierto, como dice el autor, que Sánchez Silva quizás no fue más que coherente con su ideal liberal de igualdad de todos los españoles, pero seguimos sin saber -porque no hay rastros- el motivo concreto por el que el diputado utrerano sostuvo durante décadas su insistente discurso antiforal.

Aunque el autor se centra en sus debates más conocidos, al ser una biografia parlamentaria, detalla y analiza sus otros discursos y además en su contexto, es decir, en relación con el momento político de cada momento, por lo que se nos hace fácil entender tanto unas posturas como otras y así nos muestra la actividad parlamentaria de un diputado y senador con larga trayectoria y además en coyunturas muy diversas, por lo que nos muestra también su propia evolución a lo largo del tiempo -siempre manteniendo el crónico tema foral- en 
muy diversos temas. En definitiva, además de abordar el aspecto meramente biográfico Diego Caro analiza toda una evolución personal, política $\mathrm{y}$ parlamentaria con lo que nos ilustra perfectamente las cuatro décadas de actividad de un personaje tan conocido, pero tan desconocido en el fondo, como fue Sánchez Silva.

Enviado el (Submission Date): 25/09/2017

Aceptado el (Acceptance Date): 12/11/2017 